\title{
Rheumatoid pneumoconiosis (Caplan's syndrome)
}

\author{
Zeineb Alaya $^{1 *}$, Mouna Braham ${ }^{1}$, Sana Aissa ${ }^{2}$, Houda Kalboussi ${ }^{3}$ and Elyès Bouajina ${ }^{1}$ \\ ${ }^{1}$ Department of Rheumatology, Farhat Hached Hospital, Faculty of Medicine of Sousse, Sousse, Tunisia \\ ${ }^{2}$ Department of Pneumology, Farhat Hached Hospital, Faculty of Medicine of Sousse, Sousse, Tunisia \\ ${ }^{3}$ Department of Medical Work, Farhat Hached Hospital, Faculty of Medicine of Sousse, Sousse, Tunisia
}

\begin{abstract}
Background: Caplan's syndrome is defined as the association between silicosis and rheumatoid arthritis (RA). It is a rare and usually diagnosed in an advanced stage of RA course. It affects generally patients with long exposure to silica. Here we report a case of a patient diagnosed with RA after diagnosed silicosis.

Case presentation: A 58-year-old man, had worked for 21 years as a truck driver with exposure to silica, until the age of 52, when he developed dyspnea with polyarthritis involving wrists and ankles. He had dyspnea in effort. The pulmonary auscultation revealed crepitus in the basal segments. The exploration of respiratory function (EFR) showed a mild restrictive ventilatory deficit without alveolocapillary diffusion abnormalities. Chest X-rays revealed multiple micro-nodules distributed throughout the lungs but predominantly in lower segments. The bronchoalveolar lavage showed a predominance of macrophagic cells with predominance of $30 \%$ of siderophages. The CT scan of the chest showed a pulmonary fibrosis. The diagnosis of silicosis was made and then he was referred to the rheumatology department, for exploration of chronic symmetrical polyarthritis. On physical examination, he presented synovitis in the shoulders, wrists, hands and in the right knee. The $\mathrm{X}$-Ray showed bilateral erosions in the fifth metatarsal of both feet. Rheumatoid factor and anti-cyclic citrullinated peptide antibodies were positive. The patient was diagnosed with RA. The patient received corticosteroids and rituximab.
\end{abstract}

Conclusion: The exact etiology of Caplan's syndrome is not clear but prolonged exposure to silica seems to be the first factor incriminated in its pathogenesis.

\section{Introduction}

Occupational exposure to silica has been implicated in the development of autoimmune inflammatory diseases [1]. Its association with rheumatoid arthritis (RA) is well recognized [1], and is known as 'Caplan's syndrome' or also 'Rheumatoid pneumoconiosis' (RP). It is a rare syndrome which can also occur in workers exposed to silica as well as in patients with silicosis or asbestosis [2]. It was identified in 1953 by Caplan [3] and consists of multiple well-defined rounded nodules on chest X-ray, distributed throughout the lungs predominantly at the periphery [4]. The prevalence of this syndrome among patients with pneumoconiosis is low [4]. The prevalence of $0.4 \%$ was found by Caplan [3], more recently, in a comparative study, Honma and Vallyathan showed an incidence of $0.75 \%$ in Japan and $1.5 \%$ in the USA [5]. Here we reported a case of Caplan's syndrome in patient with diagnosed silicosis.

\section{Case presentation}

A 58-year-old man, who did not smoke, had worked for 21 years as a truck driver with exposure to silica, until the age of 52, when he developed dyspnea with polyarthritis involving wrists and ankles. He was referred to the Pneumology department in Farhat Hached Hospital in Sousse in Tunisia. He had dyspnea in effort stage II basing on NYHA classification. The pulmonary auscultation revealed crepitus in the basal segments. The exploration of respiratory function (EFR) showed a mild restrictive ventilatory deficit without alveolocapillary diffusion abnormalities. Chest X-rays revealed multiple micro-nodules distributed throughout the lungs but predominantly in lower segments (Figure 1). The bronchoalveolar lavage showed a predominance of macrophagic cells with predominance of $30 \%$ of siderophages. The CT scan of the chest showed a pulmonary fibrosis with septal and intralobular crosslinks in the two lung bases predominantly on the left side and at the upper lingual lobe (Figure 2). The diagnosis of silicosis was made in 2011 . Then in 2016 he was referred to the rheumatology department, for exploration of chronic symmetrical polyarthritis. On physical examination, he presented synovitis in the shoulders, wrists, hands (Figure 3) and in the right knee. The X-Ray showed bilateral erosions in both hands (Figure 4) and feet (Figure 5). Rheumatoid factor (RF) found by the Latex and Rose-Waaler reaction and anticyclic citrullinated peptide antibodies (ACCP) measured by ELISA were highly positive (500 UI and $170 \mathrm{UI} / \mathrm{L}$ respectively). The patient was diagnosed with RA basing on the American College of Rheumatology (ACR)/European League against Rheumatism (EULAR) classification criteria of RA [6]. The disease activity score (DAS28) [7] was up for 7.52. The diagnosis of Caplan's Syndrome was made. The patient received corticosteroids and rituximab (Mabthera) with an improvement in polyarthritis with a 12 months follow-up.

\section{Discussion}

The caplan's syndrome is first described by Caplan in 1953 [3], observed on coalworkers of South Wales. It consists in the association between silicosis and RA [2]. The radiological features consist in

Correspondence to: Zeineb Alaya, Department of Rheumatology, Farhat Hached Hospital, Faculty of medicine of Sousse, Ibn el Jazzar Street, 4000 Sousse, Tunisia, Tel: +21698375975; E-mail: zeineb_a@hotmail.fr

Key words: Caplan's syndrome, Rheumatoid Arthritis, silicosis, chest CT scan, rituximab.

Received: October 04, 2017; Accepted: October 28, 2017; Published: October 30,2017 


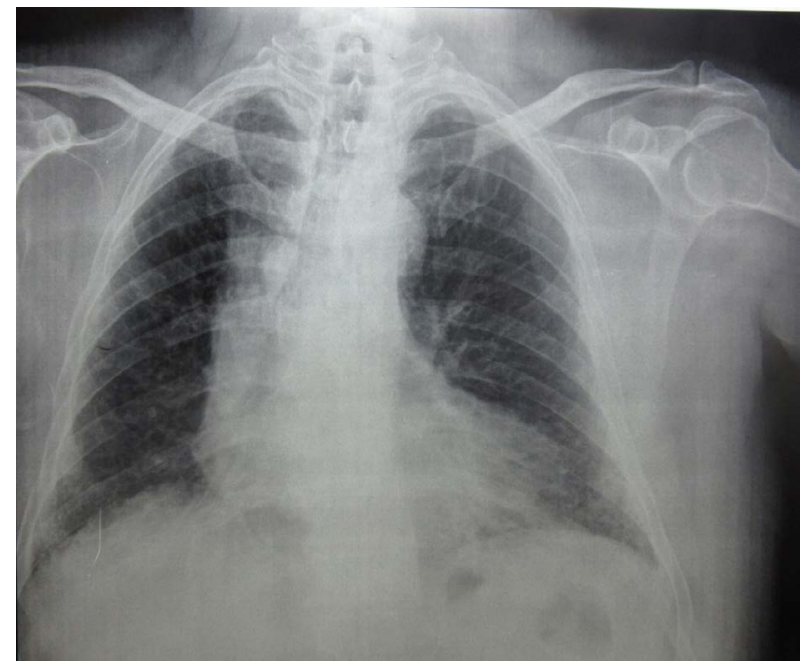

Figure 1. Chest X-ray showing multiple micro-nodules distributed throughout the lungs but predominantly in lower segments.

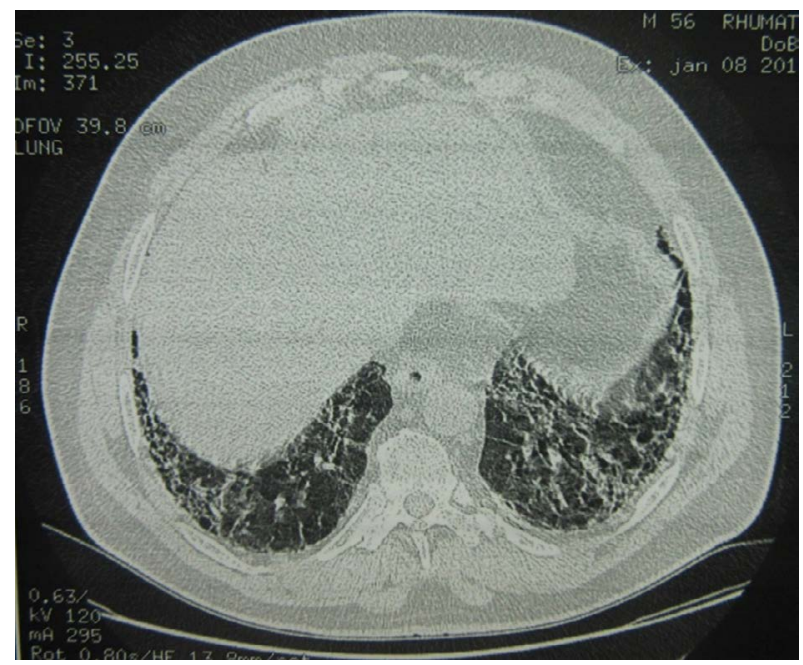

Figure 2. CT scan of the chest showing a pulmonary fibrosis with septal and intralobular crosslinks in the two lung bases predominantly on the left side and at the upper lingual lobe.

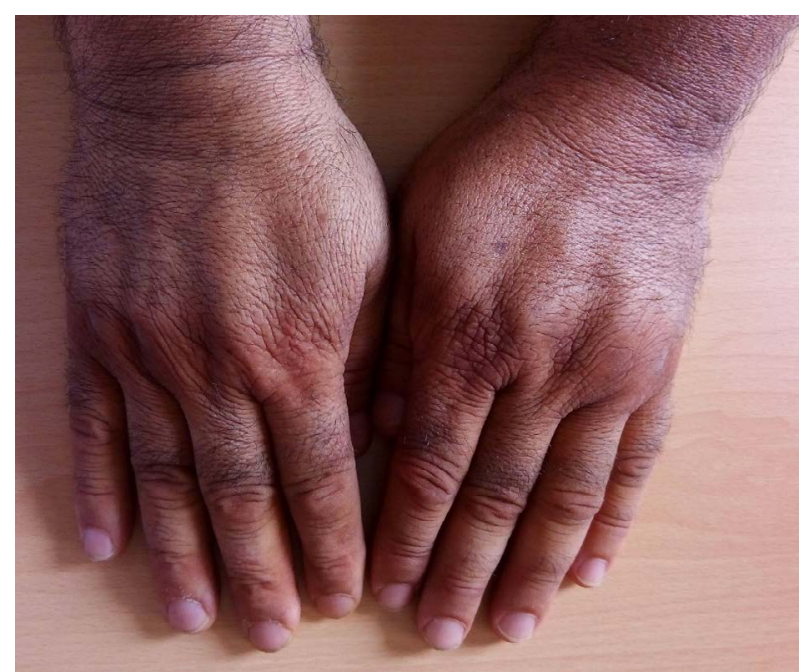

Figure 3. Picture of the patients' hands showing synovitis in both wrists and small joints of the hands.

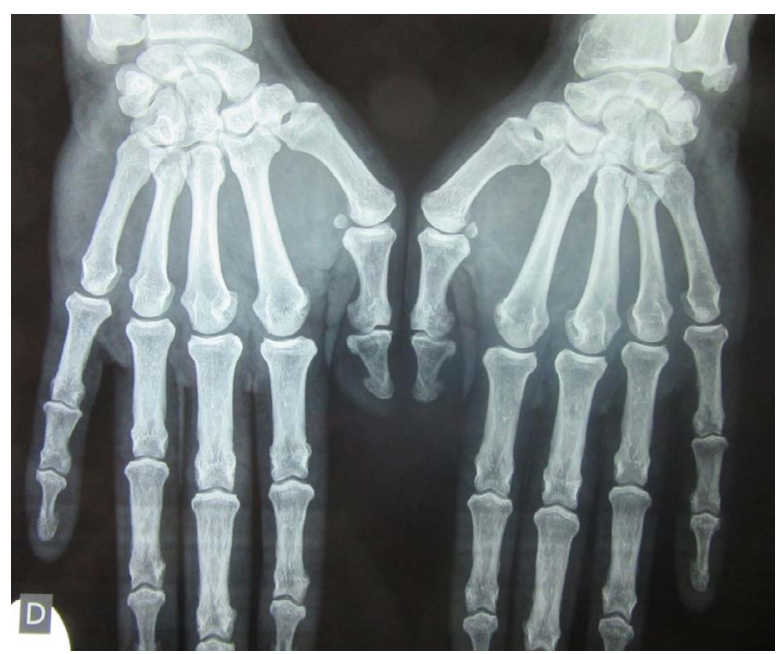

Figure 4. Radiography of hands showing erosions in the left radial extremity, in the right carpe, in the first left inter-phalangeal joint and in the second and third right metacarpophalangeal joint.

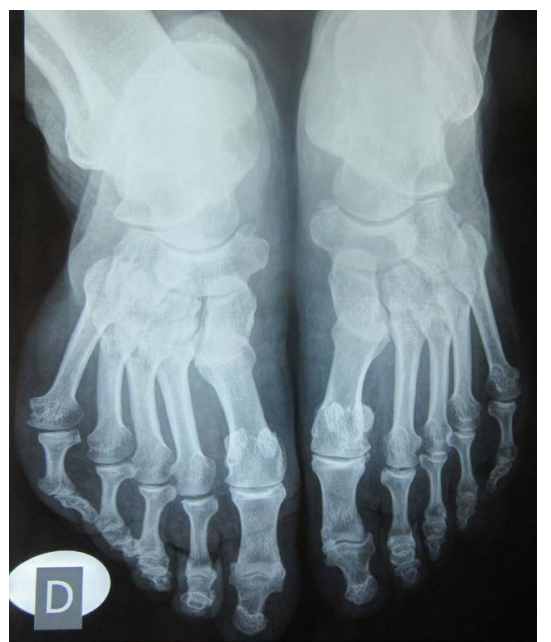

Figure 5. Radiography of feet showing concentric joint space narrowing in the first metatarsophalangeal joints with erosions in both fifth metatarsophalangeal joints and in the fourth right metatarsophalangeal joint.

multiple well-defined round opacities, measured between 0.5 and $5 \mathrm{~cm}$ in diameter, distributed throughout both lung fields but predominantly at the periphery [8]. The association between long exposure to silica, pneumoconiosis and RA is proved [9]. In the study of Calvert GM et al. [10], the link between crystalline silica exposure and RA is well demonstrated. Both RA and rheumatoid factor is more frequent in patients with Caplan's syndrome compared to exposed miners with or without simple pneumoconiosis [11].

The pathological classic type of "Caplan nodules" is that they contain a central necrotic area which is surrounded by alternate necrotic tissue and layers of black coal dust, with a peripheral zone of cellular infiltration containing polymorphonuclear granulocytes, occasional giant cells and macrophages [12]. These macrophages may contain dust particles [12]. The exact pathogenesis of RA is still unclear. The hypothesis is that silica particles are ingested by alveolar macrophages leading to inflammation and activation of fibroblasts. The macrophages destroyed the silica which is again digested by new macrophages [13]. Activated macrophages by silica via the pathogen associated molecular pattern (PAMP) will cause the production of 
several cytokines including interleukin-1 and TNF-alpha. Following the activation of the innate immune system, dendritic cells will present antigens to CD4 T lymphocytes [13]. This repeated process causes chronic immune activity and fibrosis, and so facilitates the formation of autoantigens [12]. Pneumoconiosis results in the increase of autoantibodies, immune complexes, and excess production of immunoglobulins including the RF [12]. Also, Positive ACCP were frequently found in Caplan's syndrome and there is a link between exposure to silica and ACPA-positive RA [14].

From the radiological and exposure history points of view, the clinical case we present here meets the criteria established for the diagnosis of Caplan's syndrome. We emphasize the importance of the occupational anamnesis in RA cases with radiological opacities different from the pulmonary alterations that are the most typical of the disease. This case also illustrates the potential of free silica and other mineral dusts to trigger autoimmune diseases.

Concerning treatment, there is not a conventional protocol. The treatment should be discussed case by case and performed according to the rheumatological guidelines, irrespective of Caplan's syndrome [2]. Generally, as well as other pneumoconioses, Silicosis, does not respond to medical treatment [4].

\section{Conclusion}

Although rare, rheumatoid pneumoconiosis, also known as Caplan's syndrome, can occur in workers exposed to silica, as well as in patients with silicosis. Aspects of diagnosis, classification and occurrence of this syndrome are discussed, emphasizing the importance of the occupational anamnesis of patients with rheumatoid arthritis and lung opacities on chest X-rays.

\section{Conflict of interest}

None.

\section{References}

1. Costallat LTL, De Capitani EM, Zambon L (2002) Silicose pulmonaire et lupus érythémateux disséminé chez l'homme. À propos de deux observations. Rev Rhum 69: 76-79.
2. Alaya R, Zouche I, Kaffel D, Riahi H, Hamdi W, Kchir MM (2017) Caplan's syndrome in an elderly-onset rheumatoid arthritis patient: About a new case. The Egyptian Rheumatologist.

3. Caplan A (1953) Certain unusual radiological appearances in the chest of coal-miners suffering from rheumatoid arthritis. Thorax 8: 29-37. [Crossref]

4. Schreiber J, Koschel D, Kekow J, Waldburg N, Goette A, et al. (2010) Rheumatoid pneumoconiosis (Caplan's syndrome). Eur J Intern Med 21: 168-172. [Crossref]

5. Honma K, Vallyathan V (2002) Rheumatoid Pneumoconiosis: A comparative study of autopsy cases between Japan and North America. Annals of Occupational Hygiene 46: 65-67.

6. Aletaha D, Neogi T, Silman AJ, Funovits J, Felson DT, et al. (2010) 2010 Rheumatoid arthritis classification criteria: an American College of Rheumatology/European League Against Rheumatism collaborative initiative. Arthritis Rheum 62: 2569-2581. [Crossref]

7. Prevoo ML, van 't Hof MA, Kuper HH, van Leeuwen MA, van de Putte LB, et al. (1995) Modified disease activity scores that include twenty-eight-joint counts. Development and validation in a prospective longitudinal study of patients with rheumatoid arthritis. Arthritis Rheum 38: 44-48. [Crossref]

8. TELLESSON WG (1961) Rheumatoid pneumoconiosis (Caplan's syndrome) in an asbestos worker. Thorax 16: 372-377. [Crossref]

9. Otsuki T, Miura Y, Nishimura Y, Hyodoh F, Takata A, et al. (2006) Alterations of Fas and Fas-related molecules in patients with silicosis. Exp Biol Med (Maywood) 231: 522-533. [Crossref]

10. Calvert GM, Rice FL, Boiano JM, Sheehy JW, Sanderson WT (2003) Occupational silica exposure and risk of various diseases: an analysis using death certificates from 27 states of the United States. Occup Environ Med 60: 122-129. [Crossref]

11. Miall WE, Caplan A, Cochrane AL, Kilpatrick GS, Oldham PD (1953) An epidemiological study of rheumatoid arthritis associated with characteristic chest $\mathrm{x}$-ray appearances in coal-workers. Br Med J 2: 1231-1236.

12. Weili G, Zhang N (2016) A Case Report of Rheumatoid Pneumoconiosis (Caplan Syndrome). Chest 149: A469.

13. De Capitani EM, Schweller M, Silva CM, Metze K, Cerqueira EM, et al. (2009) Rheumatoid pneumoconiosis (Caplan's syndrome) with a classical presentation. J Bras Pneumol 35: 942-946. [Crossref]

14. Yahya A, Bengtsson C, Larsson P, Too CL, Mustafa AN, et al. (2014) Silica exposure is associated with an increased risk of developing ACPA-positive rheumatoid arthritis in an Asian population: evidence from the Malaysian MyEIRA case-control study. Mod Rheumatol 24: 271-274. [Crossref]

Copyright: (C2017 Alaya Z. This is an open-access article distributed under the terms of the Creative Commons Attribution License, which permits unrestricted use, distribution, and reproduction in any medium, provided the original author and source are credited. 